\title{
Nuclear receptor research in zebrafish
}

\author{
Marcel J M Schaaf \\ Institute of Biology (IBL), Leiden University, Leiden, The Netherlands
}

Correspondence should be addressed to M J M Schaaf Email m.j.m.schaaf@biology. leidenuniv.nl

\begin{abstract}
Nuclear receptors (NRs) form a superfamily of transcription factors that can be activated by ligands and are involved in a wide range of physiological processes. NRs are well conserved between vertebrate species. The zebrafish, an increasingly popular animal model system, contains a total of 73 NR genes, and orthologues of almost all human NRs are present. In this review article, an overview is presented of NR research in which the zebrafish has been used as a model. Research is described on the three most studied zebrafish NRs: the estrogen receptors (ERs), retinoic acid receptors (RARs) and peroxisome proliferator-activated receptors (PPARs). The studies on these receptors illustrate the versatility of the zebrafish as a model for ecotoxicological, developmental and biomedical research. Although the use of the zebrafish in NR research is still relatively limited, it is expected that in the next decade the full potential of this animal model will be exploited.
\end{abstract}
Key Words
- zebrafish
- nuclear receptor
- estrogen receptor
- retinoic acid receptor
- peroxisome proliferator- activated receptor

\section{Introduction}

The nuclear receptor (NR) superfamily forms the largest family of transcription factors in metazoan organisms, in which they regulate reproduction, development, metabolism and the immune response (Bookout et al. 2006, Evans \& Mangelsdorf 2014). Many NRs become active upon binding of small lipophilic compounds, like steroid and thyroid hormones, vitamins and dietary lipids. However, about half of the NRs are designated as orphan receptors, since an activating ligand has not been identified for them. In these orphan NRs, the ligandbinding pocket is either absent or continuously occupied by a small lipid or heme molecule.

Ligand activation of NRs induces an active conformation, enabling transcriptional regulation (Moore et al. 2006). Within the NR superfamily, two modes of action exist. The first group of ligand-activated NRs already interact with their DNA recognition site before ligand binding, but since they recruit transcriptional corepressors, they are kept in an inactive state. In contrast, the members of the steroid receptor family are not bound to their DNA target sites in the absence of a ligand. Upon activation by a ligand, both groups of NRs recruit coregulator molecules, which modulate the local chromatin structure whereby the transcriptional rate of a nearby gene is either enhanced or repressed. Since their activity is not induced by a ligand, orphan receptors display constitutive transcriptional activity.

NRs share a common modular domain structure. They all contain an N-terminal domain that is variable in length, a small well-conserved DNA-binding domain (DBD) and a larger, moderately conserved, C-terminal ligand-binding domain (LBD). These common structural domains have greatly facilitated the identification of NR genes in genomic sequences and the generation of phylogenetic trees, enabling a thorough analysis of the evolution of the NR superfamily (Bertrand et al. 2004, Escriva et al. 2004, Markov et al. 2008, Bridgham et al. 2010). Evolutionary studies have demonstrated that the NR superfamily has evolved from a single ligand-activated ancestral receptor. Through a process of gene duplication http://jme.endocrinology-journals.org DOI: 10.1530/JME-17-0031
() 2017 Society for Endocrinology Printed in Great Britain
Published by Bioscientifica Ltd 
and subsequent mutation, the capacity to bind different ligands and the ligand-independent activation were acquired. Phylogenetic analysis has led to the classification of the NR superfamily into seven subfamilies (NR0-6) on which the current nomenclature of the NR superfamily is based.

The zebrafish was initially used as a model system for studies on embryonic development and morphogenesis. Its easy maintenance, high fecundity and optical transparency made it a highly versatile research model. Forward and reverse genetic studies in zebrafish were facilitated when the complete genomic sequence of the zebrafish became available. Since embryos and larvae were small in size and could easily be obtained in large numbers, large-scale studies could be performed. Since most compounds can easily penetrate the skin of these organisms, drug and toxicological screenings can be performed by simply adding the compounds to the water. The generation of mutant and transgenic fish lines opened up new possibilities for zebrafish research, and novel genome-editing techniques like CRISPR/Cas9 will further advance the field. As a result, over the last decade, the zebrafish has emerged as an important model system not only for research on vertebrate development (Beis \& Stainier 2006, Collins \& Stainier 2016) but also for ecotoxicological (Dai et al. 2014) and biomedical research (Lieschke \& Currie 2007, MacRae \& Peterson 2015). In this review, an overview is presented of the research on NRs using the zebrafish as a model system.

Ten years ago, Bertrand et al. (2007) found 70 NR genes in the zebrafish genome. When they compared the zebrafish NR family to its mammalian equivalent (48 NR genes in the human genome, 49 in the mouse genome), they could not find zebrafish orthologues of RAR $\beta$, LXR $\beta$ and CAR. Actually, LXR $\beta$ and CAR have not been identified in any fish species. Compared to mammals, 19 NR genes were found to be duplicated in zebrafish, as a result of a genome duplication that occurred in the teleost lineage soon after the divergence from the tetrapods (Glasauer \& Neuhauss 2014): TR $\alpha$, RAR $\alpha, \operatorname{RAR} \gamma$, PPAR $\alpha, \operatorname{PPAR} \beta$, RevErbA $\beta$, Rev-ErbA $\gamma$, ROR $\alpha$, ROR $\gamma$, VDR, RXR $\alpha$, RXR $\beta$, COUPTFI, EAR2, ER $\beta$, ERR $\beta$ or $\gamma$, SF-1, GCNF and SHP. Although the official nomenclature for duplicate NRs in (zebra) fish is the addition of ' $-\mathrm{A}$ ' or ' $-\mathrm{B}$ ' suffixes (e.g. PPAR $\beta-A$ and PPAR $\beta$-B, see http://zfin.org), for several receptor duplicates, the suffixes ' 1 ' and ' 2 ' are commonly used (e.g. ER $\beta 1$ and ER $\beta 2$ ). In a recent study, Zhao and coworkers (2015) found three more NR genes in the zebrafish genome: paralogues of the RXR $\gamma$ and NURR1 gene and a third paralogue of the ROR $\gamma$ gene. Thus, a total of 73 NR genes have been identified in the zebrafish genome, and an overview of the zebrafish NR superfamily is presented in Fig. 1.

The vast majority of the duplicate NR genes found in the zebrafish genome were also found in other fish species like pufferfish, medaka, tilapia and stickleback. However, differences exist as a result of lineage-specific loss of duplicate NR genes during evolution. Analysis of the relative evolution rate of the zebrafish NRs, by comparison with their human orthologue, showed that for eight duplicated NRs (PPAR $\alpha, \operatorname{RevErbA} \beta, \operatorname{ROR} \alpha, \operatorname{ROR} \gamma$, COUP-TFI, ERR $\beta$, GCNF and SHP), the evolution rate was highly different between the two proteins (Bertrand et al. 2007). This suggests neofunctionalization of the rapidly evolved copy (i.e. it has acquired a novel function), and this was confirmed by divergent expression patterns of the two NR genes (Bertrand et al. 2007). The alternative fate of duplicate genes, subfunctionalization (i.e. the two copies share the function of their nonduplicated ancestor (Force et al. 1999)), was suggested for the other duplicated NR genes.

The expression pattern of all NR genes has been analyzed using whole-mount in situ hybridizations on zebrafish embryos (Bertrand et al. 2007). The results demonstrated that most NR genes are not expressed during early embryogenesis, but start to be expressed after $24 \mathrm{~h}$ post fertilization (hpf), during organogenesis. Many of these genes are expressed in the developing central nervous system and retina, and very few in the lens, blood somites and heart. Based on the expression patterns, the zebrafish NRs could be divided in 7 clusters, and this division appeared to be very different from a similar clustering that was done based on expression of NR genes in adult mice (Bookout et al. 2006). This may indicate species-specific roles of NRs or different roles of NRs during embryonic development.

A PubMed (https://www.ncbi.nlm.nih.gov/ pubmedsearch) search, using 'zebrafish' and the name of the nuclear receptor (in as many variations as possible) as search terms, showed which NRs are being studied in zebrafish. The results of these searches are shown in Fig. 2. The searches returned a total of 678 published articles. This may be considered a small number compared to the 28,062 articles that the search term 'zebrafish' alone returns. Apparently, the zebrafish is not (yet) a very popular model system for NR research, even though among vertebrates the richest abundance of NRs is found in teleosts like the zebrafish (Zhao et al. 2015). Almost half of the published articles on zebrafish NRs involves research on steroid receptors (298), and approximately

Published by Bioscientifica Ltd 


\begin{tabular}{|c|c|c|}
\hline nr1a1 & $\operatorname{TR} \alpha$ & $\operatorname{TR} \alpha$ \\
\hline nr1a2 & $\operatorname{TR} \beta$ & \\
\hline nr1b1 & $\operatorname{RAR} \alpha$ & $\operatorname{RAR} \alpha$ \\
\hline nr1b3 & $\operatorname{RAR}_{\gamma}$ & RAR $\gamma$ \\
\hline nr1c1 & PPAR $\alpha$ & PPAR $\alpha$ \\
\hline $\mathrm{nr} 1 \mathrm{c} 2$ & PPAR $\beta$ & PPAR $\beta$ \\
\hline $\mathrm{nr} 1 \mathrm{c} 3$ & PPAR $_{\gamma}$ & \\
\hline nr1d1 & Rev-ErbA $\alpha$ & \\
\hline $\mathrm{nr} 1 \mathrm{~d} 2$ & Rev-ErbA $\beta$ & Rev-ErbA $\beta$ \\
\hline $\mathrm{nr} 1 \mathrm{~d} 4$ & Rev-ErbAy & Rev-ErbAy \\
\hline $\mathrm{nr} 1 \mathrm{f} 1$ & ROR $\alpha$ & $\mathrm{ROR} \alpha$ \\
\hline $\mathrm{nr} 1 \mathrm{f} 2$ & ROR $\beta$ & \\
\hline $\mathrm{nr} 1 \mathrm{f3}$ & $\mathrm{ROR}_{\gamma}$ & ROR \\
\hline $\mathrm{nr} 1 \mathrm{~h} 3$ & LXR $\alpha$ & \\
\hline $\mathrm{nr} 1 \mathrm{~h} 4$ & FXR $\alpha$ & \\
\hline nr1h5 & FXR $\beta$ & \\
\hline nr1i1 & VDR & VDR \\
\hline $\mathrm{nr}$ & PXR & \\
\hline
\end{tabular}
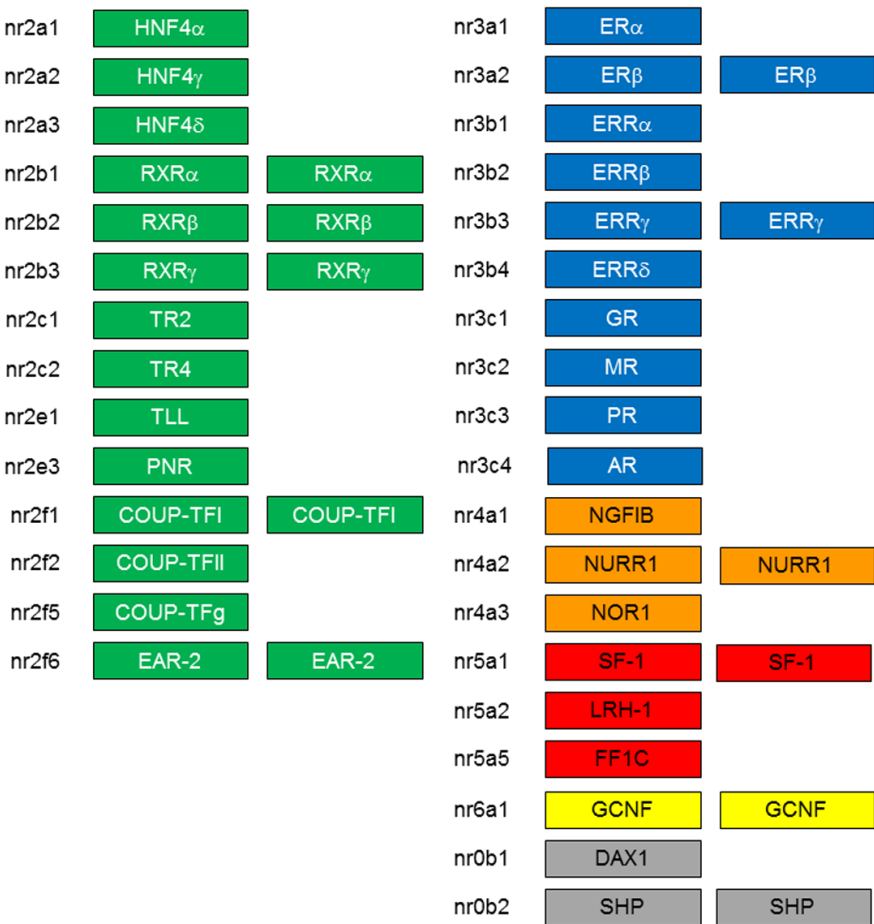

\section{Figure 1}

Overview of the nuclear receptor superfamily in zebrafish. The zebrafish genome contains 73 genes encoding nuclear receptors. No orthologues of the mammalian RAR $\beta$, LXR $\beta$ and CAR have been found, and 21 mammalian NR genes have been found to be duplicated in zebrafish. The gene encoding RORy has even been triplicated. Figure was adapted with permission from Bertrand et al. (2007). Additional information was used from Zhao et al. (2015).

half of these articles describes research on ER (155). About one-third of zebrafish NR articles deals with the NR1 family of receptors (241), with RAR (63) and PPAR (50) being the most popular subjects to study. No publications were listed on NOR1 and EAR-2 in zebrafish. In this review, research will be highlighted on the three most studied zebrafish NRs, viz. ERs, RARs and PPARs. Studies on these NRs provide an interesting overview of the research areas in which the zebrafish is currently used, ecotoxicological, developmental and biomedical research, respectively.

\section{The zebrafish estrogen receptors (ERs)}

The ER is by far the most studied NR in zebrafish. Three ER genes have been identified in zebrafish (Bardet et al. 2002, Legler et al. 2002, Menuet et al. 2002): one encoding an orthologue of the mammalian ER $\alpha$ and two encoding orthologues of ER $\beta$ (referred to as ER $\beta 1$ and ER $\beta 2$ ). These three receptors show distinct but largely overlapping expression patterns in tissues like the brain, pituitary, liver and gonads (Menuet et al. 2002). Particularly high expression levels were observed for all receptor isoforms in the neuromasts of the lateral line, a mechanoreceptive system specific to aquatic vertebrates (TingaudSequeira et al. 2004). The zebrafish ERs have been knocked down in several studies. Temporary knockdown by a morpholino of the ER $\beta 2$ expression resulted in the disrupted development of these neuromasts (absence of hair cells), which could be related to an aberrant activation of the Notch signaling pathway in the morpholinotreated embryos (Froehlicher et al. 2009). Knockdown of ER $\alpha$ expression during embryonic stages by morpholinoinduced blocking of translation of maternal transcripts resulted in severe developmental defects and early mortality (Celeghin et al. 2011). Induction of specific target genes of $\mathrm{ER} \alpha$ and $\mathrm{ER} \beta 2$ could also be inhibited by morpholino knockdown of the receptor (Griffin et al. 2013). Recently, a mutant zebrafish line has been identified, carrying a mutation in the gene encoding ER $\beta 2$ (resulting in an 8 amino acid insertion in the ligand-binding domain (Lopez-Munoz et al. 2015). This mutation resulted in distorted sexual ratios (characterized by an increased adult male population), altered testicular morphology and increased testosterone and $17 \beta$-estradiol (E2) levels. In addition, these fish show a decreased immune response to a viral infection (Lopez-Munoz et al. 2015). http://jme.endocrinology-journals.org DOI: 10.1530/JME-17-0031
() 2017 Society for Endocrinology Printed in Great Britain
Published by Bioscientifica Ltd 
- TR (Thyroid hormone receptor)

$\square$ RAR (Retinoic acid receptor)

- PPAR (Peroxisome proliferator-activated receptor)

$\square$ Rev-ErbA

$\square$ ROR (RAR-related orphan receptor)

$\square$ LXR (Liver X receptor)

$\square$ FXR (Farnesoid $X$-activated receptor)

$\square$ VDR (Vitamin D receptor)

$\checkmark$ PXR (Pregnane $X$ receptor)

$\square$ HNF4 (Hepatocyte nuclear factor 4)

$\square$ RXR (Retinoid X receptor)

口 TR2/4 (Testicular receptor 2/4)

$\square$ TLL (Protein tailless homolog)

$\square$ PNR (Photoreceptor-specific nuclear receptor)

$\square$ COUP-TF (Chicken ovalbumin upstream promotertranscription factor)

$\square$ EAR-2 (V-erba-related protein-2)

- ER (Estrogen receptor)

- ERR (Estrogen-related receptor)

$\square$ GR (Glucocorticoid receptor)

$\square$ MR (Mineralocorticoid receptor)

$\square$ PR (Progestin receptor)

$\square$ AR (Androgen receptor)

- NGFIB (Nerve growth factor IB)

$\square$ NURR1 (Nuclear receptor related 1)

$\square$ NOR1 (Neuron-derived orphan receptor 1)

- SF-1 (Steroidogenic factor-1)

口 LRH-1 (Liver receptor homolog-1)

$\square$ FF1C (Fushi tarazu factor 1C)

$\square$ GCNF (Germ cell nuclear factor)

$\square$ DAX1 (Dosage-sensitive sex reversal, adrenal hypoplasia critical region, on chromosome $X$, gene 1)

$\square$ SHP (Small heterodimer partner)

\section{Figure 2}

Results of a PubMed (https://www.ncbi.nlm.nih.gov/pubmedsearch) literature search using 'zebrafish' and the name of the nuclear receptor (in as many variations as possible) as search terms. The pie chart indicates the relative number of articles on a specific NR within the total number of publications on the NR superfamily in zebrafish. The searches returned a total of 678 published articles, of which approximately fifty percent involves research on steroid receptors (298), and approximately half of these articles describe research on ER (155). Receptors of the NR1 family are studied in about one-third of zebrafish NR articles (241), with RAR (63) and PPAR (50) being the most studied NRs in this family. NOR1 and EAR-2 have not been studied in zebrafish.

Further analysis of the literature revealed that about half of the published articles on the zebrafish ER involves research on the role of this receptor as a mediator of the activity of endocrine-disrupting chemicals (EDCs). EDCs are natural or synthetic compounds that occur in the environment and disrupt the function, levels and distribution of endogenous hormones of exposed organisms, by mimicking or antagonizing the actions of hormones, or by modulating hormone synthesis and metabolism (Colborn et al. 1993). This may ultimately lead to altered development and/or reproduction in humans and wildlife. EDCs form a heterogeneous group of substances, encompassing natural (e.g. E2) and synthetic hormones (e.g. diethylstilbestrol (DES), and 17 $\alpha$-ethinylestradiol (EE2)), phytoestrogens (e.g. genistein), and seemingly unrelated compounds like pesticides (e.g. dichlorodiphenyltrichloroethane (DDT)), polychlorinated biphenyls (PCBs), bisphenol A (BPA), phtalates, flavonoids and polycyclic musks (Frye et al. 2012, Gore et al. 2015). The main mechanism of action for these compounds is generally suggested to be agonistic or antagonistic interaction with the ER.

The zebrafish is widely used as a model organism to identify EDCs, and to perform risk assessment for both humans and wildlife (Segner 2009, Dang 2016). Research focuses on the development of screening assays for the activity of EDCs and their mechanism of action. Several in vivo biomarkers are used to identify EDCs in zebrafish. http://jme.endocrinology-journals.org DOI: 10.1530/JME-17-0031
(C) 2017 Society for Endocrinology Printed in Great Britain 
The concentration of vitellogenin (VTG) is the most widely used biomarker for EDC activity, in particular for compounds that activate ER (Dang 2016). VTG is an egg yolk precursor protein, which is produced and secreted by the liver, taken up by the ovary and modified by developing eggs to form the egg yolk. VTG synthesis is under tight hormonal control. Hepatic production of VTG is induced by estrogens, and in male and immature fish, low levels of VTG can be detected under normal conditions. In the zebrafish genome, seven VTG genes are present, and their expression level can be monitored at the mRNA and protein level, in blood, organ and wholebody homogenates. Induction of VTG synthesis in male fish by estrogens occurs rapidly and can be detected within $24 \mathrm{~h}$, which makes this assay suitable for shortterm screening of EDCs. However, induction of VTG does not provide conclusive evidence on the mechanism of action of the identified EDC. It has been well established that ER activation induces VTG production, but recent studies have shown that AR, PR and GR activation may result in altered VTG levels as well (Dang 2016).

To identify novel molecular biomarkers for ER activity, several transcriptomic analyses have been performed (Baker \& Hardiman 2014). Adult male and female fish have been exposed to EE2, and their liver and telencephalon transcriptome have been determined using microarray analysis (Martyniuk et al. 2007, Hoffmann et al. 2008). In another study, whole-body transcriptome analysis was performed on male adults after exposure to E2 (Lam et al. 2011). Finally, a microarray was performed during early developmental stages (1, 2, 3 and 4 days post fertilization (dpf) (Hao et al. 2013)). In addition to well-known ER target genes like $v \operatorname{tg} 1$ (the only gene induced by estrogens at all stages studied (Hao et al. 2013)), vtg3, vtg4 and esr 1 , these studies also revealed many metabolic genes (Martyniuk et al. 2007, Hoffmann et al. 2008) and genes involved in cell cycle and DNA repair (Lam et al. 2011) as being regulated by ER.

An alternative approach for short-term screening of EDCs is the monitoring of transgenic reporter fish in which an ER-responsive promoter is genetically coupled to a gene encoding a reporter protein like luciferase or green fluorescent protein (GFP). Using a transgenic line with the luciferase gene coupled to a promoter with a single estrogen response element (ERE), estrogenic activity could be measured after 96-h exposure to EDCs by measuring the luciferase activity in tissue homogenates. This assay has been performed using adult zebrafish and juveniles ( $30 \mathrm{dpf}$ ). The latter, which are at the stage of gonad differentiation, appear to be more responsive (Legler et al. 2000,
Legler et al. 2002, Bogers et al. 2006). In addition, two transgenic zebrafish lines have been generated in which GFP is used, enabling microscopic analysis of the reporter activity. In the first line, a promoter with 5 EREs was utilized (Gorelick \& Halpern 2011). After estrogen exposure, GFP expression was observed in embryonic and larval zebrafish in the brain, liver and pancreas (Gorelick \& Halpern 2011, Hao et al. 2013), consistent with the location of erb2 expression during these developmental stages (Gorelick \& Halpern 2011). Estrogen treatment of larvae also induced expression of GFP in cells in the ventral fin adjacent to the cloaca, in the developing olfactory organ and in the heart. This induction appeared to be dependent on ER (it could be inhibited by the ER antagonist ICI 182,780 (fulvestrant)), although ER expression in these regions was not detectable by in situ hybridization at these stages. Interestingly, GFP induction by EDCs like EE2, BPA and genistein showed marked differences in the tissue specificity of the response (Gorelick \& Halpern 2011). In adult fish, males showed no GFP expression in the liver, whereas displayed dim expression, which could be increased upon estrogen exposure. Ovaries and (male and female) pituitaries were GFP-positive without exposure to exogenous estrogens, so this was considered to reflect ER activation by endogenous estradiol. In a second transgenic line, GFP was coupled to the promoter of the brain aromatase $\mathrm{b}$ gene (cyp19a1b), resulting in specific GFP expression in radial glial cells in the area bordering the brain ventricles (Tong et al. 2009). Before $9 \mathrm{dpf}$, the GFP expression is only observed after induction by estrogens, enabling screening estrogenic activity of EDCs using exposure from 0 to $5 \mathrm{dpf}$ (Brion et al. 2012). To investigate which receptor isoform mediates the effect of EDCs, reporter zebrafish liver cell lines are available in which an ER:luciferase construct has stably been transfected together with an expression vector for ER $\alpha$, ER $\beta 1$ or ER $\beta 2$ (Cosnefroy et al. 2012). These cell lines have now replaced assays in which reporter constructs and expression vectors were transiently transfected in human cells (Le Page et al. 2006, Sassi-Messai et al. 2009).

Phenotypic endpoints like growth, sexual differentiation, sex ratio, egg production and fertilization success are commonly used for monitoring EDC activity, and these biomarkers are used in partial and full life-cycle studies (Segner 2009, Dang 2016). Partial life-cycle studies may involve investigating the impact of short-term exposure in mature actively reproducing individuals, and in these studies, endpoints like fertilization success and fecundity are measured, which may be complemented by gonad histopathology or plasma levels of sex steroids

Published by Bioscientifica Ltd 
or VTG. Alternatively, fish may be exposed during a sensitive period in their development, generally between 0 and $60-70 \mathrm{dpf}$, and then the key endpoint is sexual differentiation, determined using parameters like gonad histopathology and sex ratio. Unlike other small fish model species like fathead minnow and medaka, zebrafish do not display secondary sex characteristics that are quantifiable and can be used as biomarkers for endocrine disruption. Full life-cycle testing involves exposure from fertilization until the reproductive age. These studies have the advantage of monitoring both developmental and reproductive effects of EDCs, but suffer from the disadvantage that they are more costly and resource intensive than partial life-cycle studies. In 2012, the Organisation for Economic Cooperation and Development (OECD) published a guidance document providing guidelines for various types of in vitro and in vivo EDC screening assays (OECD 2012). Among these assays, several standardized in vivo tests which may be performed in zebrafish are described, like the Fish ShortTerm Reproduction Assay (OECD 2009a), the 21-Day Fish Assay (OECD 2009b), the Fish Sexual Development Test (FSDT (OECD 2011)) and the Fish Lifecycle Toxicity Test (FLCTT (EPA 1996)).

In recent years, zebrafish embryos and larvae have been used to unravel the mechanism of action of several EDCs. It was shown by using morpholinos and antagonists that the disruption of the migration and distribution of primordial germ cells by EE2 are mediated by ER $\beta 1$ (Hu et al. 2014). Using receptor antagonists, the behavioral effects of flavonoids were demonstrated to be independent of ER activity (Bugel et al. 2016). Finally, BPA has been shown to induce otolith malformations during development (Gibert et al. 2011). Although it is commonly suggested that ER is the receptor mediating this effect, it was shown that these malformations are ERR $\gamma$ dependent using morpholino knockdown and overexpression by mRNA injection (Tohme et al. 2014).

\section{The zebrafish retinoic acid receptors (RARs)}

Retinoic acid (RA) is the active metabolite of vitamin A. The importance of vitamin A in embryonic development has been recognized since ancient times, even though its molecular identity was not elucidated until the twentieth century. Over the last century, the relevance of vitamin A in vertebrate development has been established experimentally in a large number of nutritional studies in mammalian and avian animal models (Mark et al. 2009,
Metzler \& Sandell 2016, Wiseman et al. 2016). In all studies, newborns from mothers fed vitamin A-deficient diets showed an array of severe malformations. Collectively, these malformations are now known as vitamin A deficiency (VAD) syndrome, and include defects in the development of the eye and other organs like the lungs, kidneys and heart. Developmental abnormalities do not only occur under conditions of deficiency, but exposure to excess vitamin A or one of its metabolites can be equally detrimental to embryonic development, indicating that levels of these compounds should be tightly regulated.

The effects of RA are mediated by the RARs and RXRs, which form heterodimers. RARs are activated by RA and are only dimerized with RXRs, whereas RXRs do not require ligand binding for their activity and can also dimerize with other NRs like TRs, PPARs, VDRs and LXRs. In tetrapods, three RARs encoded by different genes have been identified: RAR $\alpha, \operatorname{RAR} \beta$ and RAR $\gamma$. In the zebrafish genome, no gene encoding the RAR $\beta$ isoform was found, whereas 2 genes encoding an RAR $\alpha$ isoform (Hale et al. 2006, Waxman \& Yelon 2007) and two genes encoding an RAR $\gamma$ isoform (Tallafuss et al. 2006, Waxman \& Yelon 2007) were identified. In situ hybridizations for all zebrafish RAR and RXR paralogues showed overlapping and distinct areas of expression (Waxman \& Yelon 2007).

The tight regulation of the RA concentration during embryogenesis is for a large part controlled through complementary expression of RA-synthesizing and RA-degrading enzymes. RA is biosynthesized from vitamin A in a two-step process. First, vitamin A is converted into retinaldehyde, and this step is catalyzed by alcohol dehydrogenases (ADHs) or retinol dehydrogenases (RDHs). Second, retinaldehyde is oxidized to RA, and this step requires retinal dehydrogenases, members of the aldehyde dehydrogenase (ALDH) family. Whereas humans express three ALDH enzymes that catalyze this reaction, only two are present in zebrafish (Aldha2 and Aldha3 (Pittlik et al. 2008)). Biodegradation of RA into 4-hydroxy-RA is controlled by enzymes of the Cytochrome P450 26 (Cyp26) subfamily. Zebrafish, like mammals, express three subtypes: Cyp26a1, Cyp26b1 and Cyp26c1.

The importance for vertebrate embryogenesis of these enzymes controlling the RA concentrations has clearly been demonstrated in a variety of studies (reviewed in Samarut et al. 2015). In general, these studies show that during early embryogenesis RA is involved in anterior/posterior patterning, promoting the formation of posterior structures like the rhombomeres in the hindbrain, at the expense of anterior structures like eyes http://jme.endocrinology-journals.org DOI: 10.1530/JME-17-0031
() 2017 Society for Endocrinology Printed in Great Britain
Published by Bioscientifica Ltd 
and the forebrain. To control early embryogenesis, RA concentrations are high in posterior tissues, mainly due to high Aldh1a2 expression in the posterior mesoderm, and low RA levels are found in anterior regions, mainly as a result of Cyp26a1 activity. This gradient has elegantly been visualized using a RARE:YFP transgenic line in which the expression of Yellow Fluorescent Protein (YFP) is driven by retinoic acid response elements (RAREs) (PerzEdwards et al. 2001, White et al. 2007). More recently, a transgenic line was generated expressing so-called genetically encoded probes for RA (GEPRAs) that can be used to measure RA levels directly (Shimozono et al. 2013). These probes are made of the RAR LBD fused to a pair of fluorescent proteins. A conformational change in the LBD upon RA binding induces fluorescence resonance energy transfer (FRET) between the two fluorescent proteins, and this FRET signal can be readily detected. In addition to studies using these reporter lines, the relevance of enzymes that regulate the RA gradient has been studied using chemical inhibitors, selective knockdown of genes using morpholinos or CRISPR/Cas9 technology or using mutants identified in forward-genetic screens, in which the offspring zebrafish, randomly mutagenized by treatment with N-ethyl-N-nitrosourea (ENU), was screened for developmental abnormalities.

In two forward-genetic screens, mutant lines were generated with a mutation in the gene encoding the RA biosynthesis enzyme Aldh1a2 (neckless (Begemann et al. 2001) and no-fin (Grandel et al. 2002)). These mutants displayed defects in the hindbrain and midline mesendodermal tissues, and absence of pectoral fins and cartilaginous gill arches, which is highly reminiscent of VAD in other animal models. However, the hindbrain phenotype was less severe than observed in these other models, which was explained by maternal Aldh1a2 activity. This was demonstrated in a study in which two aldh1a2 morpholinos were compared (Alexa et al. 2009): a translation-blocking morpholino (affecting expression from all mRNAs) which induced a similar phenotype as chemical inhibition of Aldh1a2, and a splice-blocking morpholino (affecting expression form only zygotic mRNAs) which displayed a less severe phenotype. Morpholino knockdown of the expression of another enzyme of this subfamily, Aldh1a3, did not result in hindbrain defects, but aberrant eye development was observed (Yahyavi et al. 2013).

Three more mutant lines, with mutations in the cyp26a1 gene (giraffe) and cypb1 gene (stocksteif and dolphin), were derived from forward-genetic screens (Emoto et al.
2005, Laue et al. 2008, Spoorendonk et al. 2008). In the giraffe mutant, the expression of Cyp26a1affected the main RA-metabolizing enzyme during early embryonic development. This mutant displayed patterning defects in various organs including the common cardinal vein, pectoral fin, tail, hindbrain and spinal cord (Emoto et al. 2005). The lines in which the cyp26b1 gene was mutated, stocksteif and dolphin, showed severe over-ossification, which appeared to be a result of increased osteoblast activity in these mutants (Spoorendonk et al. 2008). This effect could be phenocopied by RA treatment between 84 and $96 \mathrm{hpf}$, but treatment between 48 and $54 \mathrm{hpf}$ resulted in decreased bone mineralization, probably due to inhibited osteoblast differentiation, suggesting a dual role for RA in bone development (Li et al. 2010).

To study which RAR isoform mediates the developmental effects of RA, individual isoforms were knocked down using morpholinos (Linville et al. 2009). This study showed that all four isoforms are required for anterior-posterior patterning of rhombomeres in the hindbrain. In contrast, RAR $\gamma \mathrm{A}$ was uniquely required in the cranial mesoderm for hindbrain patterning, and RAR $\alpha B$ in lateral plate mesoderm for specification of the pectoral fins. Morpholino knockdown of specific receptor isoforms combined with transcriptome analysis revealed isoform-specific transcriptional activity. Knockdown of the two RAR $\alpha$ isoforms, the two RAR $\gamma$ isoforms and all four RAR isoforms demonstrated that three classes of RA-responsive genes exist. The first class of genes requires activation of one specific isoform for their regulation, the second class of genes respond to activation of either isoform, and the third class require activation of both isoforms (Samarut et al. 2014).

\section{The zebrafish peroxisome proliferator- activated receptors (PPARs)}

PPARs are NRs which are activated by dietary lipids including saturated and unsaturated fatty acids, and by lipids involved in intracellular signaling pathways like prostaglandins and leukotrienes. By binding these ligands, they play an important physiological role as lipid sensors regulating energy metabolism and adipocyte differentiation. In addition, involvement of PPARs in vascular tone and atherosclerotic plaque formation, antiinflammatory effects and a regulatory role in myelination have been proposed. Polymorphisms in the PPAR genes have been shown to result in disturbed lipid metabolism and insulin resistance (Yong et al. 2008), and synthetic

Published by Bioscientifica Ltd. 
PPAR ligands like fibrates and thiazolidinediones have proven to be effective therapies against metabolic disorders like diabetes. They have been shown to decrease dyslipidemia and insulin resistance. As a result, PPARs are a widely studied class of NRs, in particular as drug targets for novel therapies against disease like diabetes and obesity (Berger \& Moller 2002, Feige et al. 2006).

In vertebrates, three PPARs have been identified which are encoded by three different genes: PPAR $\alpha$, PPAR $\beta$ (also called PPARס) and PPAR $\gamma$. They regulate gene expression by binding to PPAR response elements (PPREs) as a heterodimer with RXR. In silico analysis showed that the zebrafish genome contains five genes encoding PPARs: duplicate PPAR $\alpha$ and PPAR $\beta$ genes and a single gene for PPAR (Bertrand et al. 2007, McPartland et al. 2007, Den Broeder et al. 2015). Studies on PPREs in the promoter regions of zebrafish fatty acid-binding protein $(f a b p)$ genes showed that different PPAR isoforms activate specific target genes (Laprairie et al. 2016).

An in situ hybridization study showed no detectable expression of the PPAR $\alpha$-encoding genes until $5 \mathrm{dpf}$. At this time point mRNA for PPAR $\beta$-A and PPAR $\gamma$ was detectable around the swim bladder, in the liver and the intestine, and PPAR $\beta-B$ mRNA around the swim bladder (Bertrand et al. 2007). At $15 \mathrm{dpf}$, expression of the gene for PPARy was detected in terminally differentiated adipocytes located in the pancreas (which shows that it can be used as a marker for these cells), and in cells of the intestinal epithelium (Flynn et al. 2009). In adult fish, expression of this gene was observed in liver, pancreas and visceral adipose tissue (Imrie \& Sadler 2010). Immunohistochemistry revealed that PPAR $\alpha, \operatorname{PPAR} \beta$ and $\operatorname{PPAR} \gamma$ are all widely expressed after $7 \mathrm{dpf}$, and that for all isoforms, the expression level in liver is higher in early developmental stages than in adults (Ibabe et al. 2005).

In line with the variety of physiological systems affected by PPARs, many effects of these NRs have been investigated in the zebrafish model. For example, the role of PPAR $\gamma$ has been studied in a zebrafish xenograft model of gastric cancer (Cho et al. 2015), PPAR $\alpha$ activation appeared to stimulate angiogenesis in zebrafish larvae (Rizvi et al. 2013) and PPAR agonists were shown to enhance myelination, as measured by whole larvae myelin basic protein transcript levels (Buckley et al. 2010). The majority of research on the effects of PPAR activation in zebrafish has focused on lipid metabolism to develop drugs against obesity (Den Broeder et al. 2015). In most of these studies, the optical transparency of the zebrafish larvae allows for the visualization of adipocyte formation and fatty acid uptake in vivo using fluorescent lipophilic dyes like Nile Red or LipidGreen. Non-fluorescent dyes like Oil Red O or Sudan dyes are used as well, but require fixation of the larvae. Using Nile Red, a standard assay has been developed for chemical screening of potential drugs or toxic compounds (Jones et al. 2008, TingaudSequeira et al. 2011). In this zebrafish obesogenic test (ZOT), larvae are fed a standard or high-fat diet for one day, and are subsequently starved for two days with chemical treatment during the second day. Subsequently, as a measure for adiposity, whole-body lipid droplet formation was measured using Nile Red staining and fluorescence signal quantification.

In this assay, the PPAR $\gamma$ agonist rosiglitazone showed a clear obesogenic effect (Tingaud-Sequeira et al. 2011). The effect was blocked by a PPAR $\gamma$ antagonist, which on its own showed anti-obesogenic activity in the ZOT (OuadahBoussouf \& Babin 2016). Similar data were observed for a PPAR $\beta$ agonist and antagonist, whereas a PPAR $\alpha$ antagonist did not elicit an effect (Ouadah-Boussouf \& Babin 2016). In a similar study, treatment with a PPAR $\gamma$ antagonist between 3 and $5 \mathrm{dpf}$ resulted in decreased lipid droplet accumulation in the head and heart regions, suggesting decreased adipocyte differentiation (Li et al. 2010). The PPAR $\gamma$ antagonist bisphenol A diglycidyl ether (BADGE) showed a similar effect between 26 and $55 \mathrm{hpf}$, which could be inhibited by RA or endocannabinoid treatment (Fraher et al. 2015). Recently, it was suggested that the adipogenic activity of PPARy agonists involves activation of the expression of the enzyme cytosolic NADP(+) isocitrate dehydrogenase (cICDH) (Chun et al. 2014).

Although rosiglitazone was demonstrated to induce obesogenic effects in zebrafish, which were inhibited by the PPARy antagonist T0070907 (Ouadah-Boussouf \& Babin 2016), several studies have shown that this compound binds very weakly to the zebrafish PPAR $\gamma$. It appeared to be unable to activate a zebrafish PPAR $\gamma$ LBD construct in transient transfection experiments (Riu et al. 2011), and it was suggested that the replacement of human PPAR $\gamma$ Gly284 and Cys 285 by serine and tyrosine residues in the zebrafish PPAR $\gamma$ causes a weak binding affinity of rosiglitazone for the zebrafish receptor (Grimaldi et al. 2015). Apparently, the ligand specificity of zebrafish receptors does not necessarily resemble the situation in humans, and this has been shown for other NRs as well (Escriva et al. 2006, Pippal et al. 2011). These cases seem to be exceptions, since most often ligand specificity is well conserved between humans and zebrafish, but care should http://jme.endocrinology-journals.org DOI: 10.1530/JME-17-0031
() 2017 Society for Endocrinology Printed in Great Britain
Published by Bioscientifica Ltd 
be taken when pharmacological research is performed in zebrafish.

\section{Conclusion}

In this review, an overview is presented of research on NRs in which the zebrafish is used as a model system. The research on the three NRs that are most studied in zebrafish, ERs, RARs and PPARs, illustrates the versatility and advantages of this animal model system. The work performed on the action of ERs illustrates that the zebrafish is widely used in ecotoxicological research as a model for monitoring of the toxicity of environmental pollutants, due to its potential for in vivo phenotypical screening at relatively high throughput. Furthermore, the research on RARs reflects that the zebrafish model is ideally suited for developmental studies, because of its rapid external development and the suitability for forward and reverse genetic studies. The investigations performed on the action of PPARs in zebrafish display the possibilities of the zebrafish as a model system for human disease in biomedical research, since most processes underlying these diseases are well conserved between humans and zebrafish. However, the limited use of the zebrafish in NR research as compared to other animal models shows that the full potential of the zebrafish model system has not been reached in this research area. A good example of the exploitation of the advantages of the zebrafish model is the engineering of a screening system for human NR ligands and cofactors (Tiefenbach et al. 2010). In this system, an affinity tag and a GAL4 DBD were fused to a human NR LBD, and this fusion protein was expressed in zebrafish containing a UAS:GFP reporter construct. This 'Ligand Trap' system allows for high-throughput visual screening of endogenous and exogenous ligand activity, and the identification of novel NR-specific ligands and cofactors. In the next decade, it is expected that further characterization, advancement of technology and a wider availability of mutant and transgenic fish lines will increase the role of the zebrafish model system in NR research.

\section{Declaration of interest}

The author declares that there is no conflict of interest that could be perceived as prejudicing the impartiality of this review.

\section{Funding}

For the preparation of this review article, no specific grant from any funding agency in the public, commercial or not-for-profit sector was received.

\section{References}

Alexa K, Choe SK, Hirsch N, Etheridge L, Laver E \& Sagerstrom CG 2009 Maternal and zygotic aldh1a2 activity is required for pancreas development in zebrafish. PLoS ONE 4 e8261. (doi:10.1371/journal. pone.0008261)

Baker ME \& Hardiman G 2014 Transcriptional analysis of endocrine disruption using zebrafish and massively parallel sequencing. Journal of Molecular Endocrinology 52 R241-R256. (doi:10.1530/JME-13-0219)

Bardet PL, Horard B, Robinson-Rechavi M, Laudet V \& Vanacker JM 2002 Characterization of oestrogen receptors in zebrafish (Danio rerio). Journal of Molecular Endocrinology 28 153-163. (doi:10.1677/ jme.0.0280153)

Begemann G, Schilling TF, Rauch GJ, Geisler R \& Ingham PW 2001 The zebrafish neckless mutation reveals a requirement for raldh2 in mesodermal signals that pattern the hindbrain. Development 128 3081-3094.

Beis D \& Stainier DY 2006 In vivo cell biology: following the zebrafish trend. Trends in Cell Biology 16 105-112. (doi:10.1016/j.tcb.2005.12.001)

Berger J \& Moller DE 2002 The mechanisms of action of PPARs. Annual Review of Medicine 53 409-435. (doi:10.1146/annurev. med.53.082901.104018)

Bertrand S, Brunet FG, Escriva H, Parmentier G, Laudet V \& RobinsonRechavi M 2004 Evolutionary genomics of nuclear receptors: from twenty-five ancestral genes to derived endocrine systems. Molecular Biology and Evolution 21 1923-1937. (doi:10.1093/molbev/msh200)

Bertrand S, Thisse B, Tavares R, Sachs L, Chaumot A, Bardet PL, Escriva H, Duffraisse M, Marchand O, Safi R, et al. 2007 Unexpected novel relational links uncovered by extensive developmental profiling of nuclear receptor expression. PLoS Genetics 3 e188. (doi:10.1371/ journal.pgen.0030188)

Bogers R, Mutsaerds E, Druke J, De Roode DF, Murk AJ, Van Der Burg B \& Legler J 2006 Estrogenic endpoints in fish early life-stage tests: luciferase and vitellogenin induction in estrogen-responsive transgenic zebrafish. Environmental Toxicology and Chemistry 25 241-247. (doi:10.1897/05-234R.1)

Bookout AL, Jeong Y, Downes M, Yu RT, Evans RM \& Mangelsdorf DJ 2006 Anatomical profiling of nuclear receptor expression reveals a hierarchical transcriptional network. Cell 126 789-799. (doi:10.1016/j.cell.2006.06.049)

Bridgham JT, Eick GN, Larroux C, Deshpande K, Harms MJ, Gauthier ME, Ortlund EA, Degnan BM \& Thornton JW 2010 Protein evolution by molecular tinkering: diversification of the nuclear receptor superfamily from a ligand-dependent ancestor. PLoS Biology $\mathbf{8}$ e1000497. (doi:10.1371/journal.pbio.1000497)

Brion F, Le Page Y, Piccini B, Cardoso O, Tong SK, Chung BC \& Kah O 2012 Screening estrogenic activities of chemicals or mixtures in vivo using transgenic (cyp19a1b-GFP) zebrafish embryos. PLOS ONE $\mathbf{7}$ e36069. (doi:10.1371/journal.pone.0036069)

Buckley CE, Marguerie A, Roach AG, Goldsmith P, Fleming A, Alderton WK \& Franklin RJ 2010 Drug reprofiling using zebrafish identifies novel compounds with potential pro-myelination effects. Neuropharmacology 59 149-159. (doi:10.1016/j.neuropharm.2010.04.014)

Bugel SM, Bonventre JA \& Tanguay RL 2016 Comparative developmental toxicity of flavonoids using an integrative zebrafish system. Toxicological Sciences 154 55-68. (doi:10.1093/toxsci/kfw139)

Celeghin A, Benato F, Pikulkaew S, Rabbane MG, Colombo L \& Dalla Valle L 2011 The knockdown of the maternal estrogen receptor 2a (esr2a) mRNA affects embryo transcript contents and larval development in zebrafish. General and Comparative Endocrinology 172 120-129. (doi:10.1016/j.ygcen.2010.12.020)

Cho SJ, Kook MC, Lee JH, Shin JY, Park J, Bae YK, Choi IJ, Ryu KW \& Kim YW 2015 Peroxisome proliferator-activated receptor gamma upregulates galectin-9 and predicts prognosis in intestinal-type gastric cancer. International Journal of Cancer 136 810-820. (doi:10.1002/ijc.29056)

Published by Bioscientifica Ltd. 
Chun HS, Shin SH, Ahn S, Shin DS, Choi SS, Ahn JH \& Bae MA 2014 KR-62980 suppresses lipid metabolism through inhibition of cytosolic NADP isocitrate dehydrogenase in zebrafish. Zebrafish $\mathbf{1 1}$ 122-128. (doi:10.1089/zeb.2013.0919)

Colborn T, vom Saal FS \& Soto AM 1993 Developmental effects of endocrine-disrupting chemicals in wildlife and humans. Environmental Health Perspectives 101 378-384. (doi:10.1289/ ehp.93101378)

Collins MM \& Stainier DY 2016 Organ function as a modulator of organ formation: lessons from zebrafish. Current Topics in Developmental Biology 117 417-433. (doi:10.1016/bs.ctdb.2015.10.017)

Cosnefroy A, Brion F, Maillot-Marechal E, Porcher JM, Pakdel F, Balaguer P \& Ait-Aissa S 2012 Selective activation of zebrafish estrogen receptor subtypes by chemicals by using stable reporter gene assay developed in a zebrafish liver cell line. Toxicological Sciences $\mathbf{1 2 5}$ 439-449. (doi:10.1093/toxsci/kfr297)

Dai YJ, Jia YF, Chen N, Bian WP, Li QK, Ma YB, Chen YL \& Pei DS 2014 Zebrafish as a model system to study toxicology. Environmental Toxicology and Chemistry 33 11-17. (doi:10.1002/etc.2406)

Dang Z 2016 Interpretation of fish biomarker data for identification, classification, risk assessment and testing of endocrine disrupting chemicals. Environment International 92-93 422-441. (doi:10.1016/j. envint.2016.04.003)

Den Broeder MJ, Kopylova VA, Kamminga LM \& Legler J 2015 Zebrafish as a model to study the role of peroxisome proliferating-activated receptors in adipogenesis and obesity. PPAR Research 2015358029. (doi:10.1155/2015/358029)

Emoto Y, Wada H, Okamoto H, Kudo A \& Imai Y 2005 Retinoic acidmetabolizing enzyme Cyp26a1 is essential for determining territories of hindbrain and spinal cord in zebrafish. Developmental Biology $\mathbf{2 7 8}$ 415-427. (doi:10.1016/j.ydbio.2004.11.023)

EPA 1996 Ecological Effects Test Guidelines, OPPTS 850.1500; Fish Life Cycle Toxicity. (available at: https://www.epa.gov/sites/production/ files/2015-07/documents/850-1500.pdf)

Escriva H, Bertrand S \& Laudet V 2004 The evolution of the nuclear receptor superfamily. Essays in Biochemistry 40 11-26. (doi:10.1042/ bse0400011)

Escriva H, Bertrand S, Germain P, Robinson-Rechavi M, Umbhauer M, Cartry J, Duffraisse M, Holland L, Gronemeyer H \& Laudet V 2006 Neofunctionalization in vertebrates: the example of retinoic acid receptors. PLoS Genetics 2 e102. (doi:10.1371/journal.pgen.0020102)

Evans RM \& Mangelsdorf DJ 2014 nuclear receptors, RXR, and the Big Bang. Cell 157 255-266. (doi:10.1016/j.cell.2014.03.012)

Feige JN, Gelman L, Michalik L, Desvergne B \& Wahli W 2006 From molecular action to physiological outputs: peroxisome proliferatoractivated receptors are nuclear receptors at the crossroads of key cellular functions. Progress in Lipid Research 45 120-159. (doi:10.1016/j.plipres.2005.12.002)

Flynn EJ III, Trent CM \& Rawls JF 2009 Ontogeny and nutritional control of adipogenesis in zebrafish (Danio rerio). Journal of Lipid Research 50 1641-1652. (doi:10.1194/jlr.M800590-JLR200)

Force A, Lynch M, Pickett FB, Amores A, Yan YL \& Postlethwait J 1999 Preservation of duplicate genes by complementary, degenerative mutations. Genetics 151 1531-1545. (doi:10.1007/s10709-0089311-5)

Fraher D, Ellis MK, Morrison S, McGee SL, Ward AC, Walder K \& Gibert Y 2015 Lipid abundance in zebrafish embryos is regulated by complementary actions of the endocannabinoid system and retinoic acid pathway. Endocrinology 156 3596-3609. (doi:10.1210/EN.20151315)

Froehlicher M, Liedtke A, Groh K, Lopez-Schier H, Neuhauss SC, Segner $\mathrm{H} \&$ Eggen RI 2009 Estrogen receptor subtype beta2 is involved in neuromast development in zebrafish (Danio rerio) larvae. Developmental Biology 330 32-43. (doi:10.1016/j.ydbio.2009.03.005)

Frye CA, Bo E, Calamandrei G, Calza L, Dessi-Fulgheri F, Fernandez M, Fusani L, Kah O, Kajta M, Le Page Y, et al. 2012 Endocrine disrupters: a review of some sources, effects, and mechanisms of actions on behaviour and neuroendocrine systems. Journal of Neuroendocrinology 24 144-159. (doi:10.1111/j.1365-2826.2011.02229.x)

Gibert Y, Sassi-Messai S, Fini JB, Bernard L, Zalko D, Cravedi JP, Balaguer P, Andersson-Lendahl M, Demeneix B \& Laudet V 2011 Bisphenol A induces otolith malformations during vertebrate embryogenesis. BMC Developmental Biology 11 4. (doi:10.1186/1471-213X-11-4)

Glasauer SM \& Neuhauss SC 2014 Whole-genome duplication in teleost fishes and its evolutionary consequences. Molecular Genetics and Genomics 289 1045-1060. (doi:10.1007/s00438-014-0889-2)

Gore AC, Chappell VA, Fenton SE, Flaws JA, Nadal A, Prins GS, Toppari J \& Zoeller RT 2015 EDC-2: The Endocrine Society's second scientific statement on endocrine-disrupting chemicals. Endocrine Reviews $\mathbf{3 6}$ E1-E150. (doi:10.1210/er.2015-1010)

Gorelick DA \& Halpern ME 2011 Visualization of estrogen receptor transcriptional activation in zebrafish. Endocrinology 152 2690-2703. (doi:10.1210/en.2010-1257)

Grandel H, Lun K, Rauch GJ, Rhinn M, Piotrowski T, Houart C, Sordino P, Kuchler AM, Schulte-Merker S, Geisler R, et al. 2002 Retinoic acid signalling in the zebrafish embryo is necessary during presegmentation stages to pattern the anterior-posterior axis of the CNS and to induce a pectoral fin bud. Development 129 2851-2865.

Griffin LB, January KE, Ho KW, Cotter KA \& Callard GV 2013 Morpholino-mediated knockdown of ERalpha, ERbetaa, and ERbetab mRNAs in zebrafish (Danio rerio) embryos reveals differential regulation of estrogen-inducible genes. Endocrinology 154 4158-4169. (doi:10.1210/en.2013-1446)

Grimaldi M, Boulahtouf A, Delfosse V, Thouennon E, Bourguet W \& Balaguer P 2015 Reporter cell lines to evaluate the selectivity of chemicals for human and zebrafish estrogen and peroxysome proliferator activated gamma receptors. Frontiers in Neuroscience 9 212. (doi:10.3389/fnins.2015.00212)

Hale LA, Tallafuss A, Yan YL, Dudley L, Eisen JS \& Postlethwait JH 2006 Characterization of the retinoic acid receptor genes raraa, rarab and rarg during zebrafish development. Gene Expression Patterns 6 546-555. (doi:10.1016/j.modgep.2005.10.007)

Hao R, Bondesson M, Singh AV, Riu A, McCollum CW, Knudsen TB, Gorelick DA \& Gustafsson JA 2013 Identification of estrogen target genes during zebrafish embryonic development through transcriptomic analysis. PLOS ONE 8 e79020. (doi:10.1371/journal. pone.0079020)

Hoffmann JL, Thomason RG, Lee DM, Brill JL, Price BB, Carr GJ \& Versteeg DJ 2008 Hepatic gene expression profiling using GeneChips in zebrafish exposed to 17alpha-methyldihydrotestosterone. Aquatic Toxicology 87 69-80. (doi:10.1016/j.aquatox.2008.01.012)

Hu J, Sun S, Guo M \& Song H 2014 Use of antagonists and morpholinos in loss-of-function analyses: estrogen receptor ESR2a mediates the effects of 17alpha-ethinylestradiol on primordial germ cell distribution in zebrafish. Reproductive Biology and Endocrinology 1240. (doi:10.1186/1477-7827-12-40)

Ibabe A, Bilbao E \& Cajaraville MP 2005 Expression of peroxisome proliferator-activated receptors in zebrafish (Danio rerio) depending on gender and developmental stage. Histochemistry and Cell Biology 123 75-87. (doi:10.1007/s00418-004-0737-2)

Imrie D \& Sadler KC 2010 White adipose tissue development in zebrafish is regulated by both developmental time and fish size. Developmental Dynamics 239 3013-3023. (doi:10.1002/dvdy.22443)

Jones KS, Alimov AP, Rilo HL, Jandacek RJ, Woollett LA \& Penberthy WT 2008 A high throughput live transparent animal bioassay to identify non-toxic small molecules or genes that regulate vertebrate fat metabolism for obesity drug development. Nutrition and Metabolism 5 23. (doi:10.1186/1743-7075-5-23)

Lam SH, Lee SG, Lin CY, Thomsen JS, Fu PY, Murthy KR, Li H, Govindarajan KR, Nick LC, Bourque G, et al. 2011 Molecular conservation of estrogen-response associated with cell cycle regulation, hormonal carcinogenesis and cancer in zebrafish and 
human cancer cell lines. BMC Medical Genomics 441 . (doi:10.1186/1755-8794-4-41)

Laprairie RB, Denovan-Wright EM \& Wright JM 2016 Subfunctionalization of peroxisome proliferator response elements accounts for retention of duplicated fabp1 genes in zebrafish. BMC Evolutionary Biology 16 147. (doi:10.1186/s12862-016-0717-x)

Laue K, Janicke M, Plaster N, Sonntag C \& Hammerschmidt M 2008 Restriction of retinoic acid activity by Cyp26b1 is required for proper timing and patterning of osteogenesis during zebrafish development. Development 135 3775-3787. (doi:10.1242/dev.021238)

Le Page Y, Scholze M, Kah O \& Pakdel F 2006 Assessment of xenoestrogens using three distinct estrogen receptors and the zebrafish brain aromatase gene in a highly responsive glial cell system. Environmental Health Perspectives 114 752-758. (doi:10.1289/ehp.8141)

Legler J, Broekhof JLM, Brouwer A, Lanser PH, Murk AJ, Van der Saag PT, Vethaak AD, Wester P, Zivkovic D \& Van der Burg B 2000 A novel in vivo bioassay for (xeno-)estrogens using transgenic zebrafish. Environmental Science and Technology 34 4439-4444. (doi:10.1021/ es0000605)

Legler J, Zeinstra LM, Schuitemaker F, Lanser PH, Bogerd J, Brouwer A, Vethaak AD, De Voogt P, Murk AJ \& Van der Burg B 2002 Comparison of in vivo and in vitro reporter gene assays for shortterm screening of estrogenic activity. Environmental Science and Technology 36 4410-4415. (doi:10.1021/es010323a)

Li N, Kelsh RN, Croucher P \& Roehl HH 2010 Regulation of neural crest cell fate by the retinoic acid and Pparg signalling pathways. Development 137 389-394. (doi:10.1242/dev.044164)

Lieschke GJ \& Currie PD 2007 Animal models of human disease: zebrafish swim into view. Nature Reviews Genetics 8 353-367. (doi:10.1038/nrg2091)

Linville A, Radtke K, Waxman JS, Yelon D \& Schilling TF 2009 Combinatorial roles for zebrafish retinoic acid receptors in the hindbrain, limbs and pharyngeal arches. Developmental Biology 325 60-70. (doi:10.1016/j.ydbio.2008.09.022)

Lopez-Munoz A, Liarte S, Gomez-Gonzalez NE, Cabas I, Meseguer J, Garcia-Ayala A \& Mulero V 2015 Estrogen receptor 2b deficiency impairs the antiviral response of zebrafish. Developmental and Comparative Immunology 53 55-62. (doi:10.1016/j.dci.2015.06.008)

MacRae CA \& Peterson RT 2015 Zebrafish as tools for drug discovery. Nature Reviews Drug Discovery 14 721-731. (doi:10.1038/nrd4627)

Mark M, Ghyselinck NB \& Chambon P 2009 Function of retinoic acid receptors during embryonic development. Nuclear Receptor Signaling 7 e002. (doi:10.1621/nrs.07002)

Markov GV, Paris M, Bertrand S \& Laudet V 2008 The evolution of the ligand/receptor couple: a long road from comparative endocrinology to comparative genomics. Molecular and Cellular Endocrinology 293 5-16. (doi:10.1016/j.mce.2008.06.011)

Martyniuk CJ, Gerrie ER, Popesku JT, Ekker M \& Trudeau VL 2007 Microarray analysis in the zebrafish (Danio rerio) liver and telencephalon after exposure to low concentration of 17alphaethinylestradiol. Aquatic Toxicology 84 38-49. (doi:10.1016/j. aquatox.2007.05.012)

McPartland JM, Glass M, Matias I, Norris RW \& Kilpatrick CW 2007 A shifted repertoire of endocannabinoid genes in the zebrafish (Danio rerio). Molecular Genetics and Genomics 277 555-570. (doi:10.1007/ s00438-007-0207-3)

Menuet A, Pellegrini E, Anglade I, Blaise O, Laudet V, Kah O \& Pakdel F 2002 Molecular characterization of three estrogen receptor forms in zebrafish: binding characteristics, transactivation properties, and tissue distributions. Biology of Reproduction 66 1881-1892. (doi:10.1095/biolreprod66.6.1881)

Metzler MA \& Sandell LL 2016 Enzymatic metabolism of vitamin a in developing vertebrate embryos. Nutrients 8 812. (doi:10.3390/ nu8120812)

Moore JT, Collins JL \& Pearce KH 2006 The nuclear receptor superfamily and drug discovery. ChemMedChem 1 504-523. (doi:10.1002/ cmdc.200600006)
OECD 2009a Guideline for Testing of Chemicals, No. 229; Fish Short Term Reproduction Assay. (available at: http://www.oecd-ilibrary.org/ docserver/download/9712181e.pdf?expires=1486563197\&id=id\&accn ame=guest\&checksum=6C7CB4B23580CAE1F971ED96E974AA8F)

OECD $2009 b$ Guideline for the Testing of Chemicals, No. 230; 21-Day Fish Assay: A Short-Term Screening for Oestrogenic and Androgenic Activity, and Aromatase Inhibition. (available at: http://www.oecdilibrary.org/docserver/download/9723001e.pdf?expires $=1486563012 \&$ id=id\&accname=guest\&checksum=37DF1EEABB3BBDD33C8C0C90A 2F1497C)

OECD 2011 Guideline for the Testing of Chemicals, No. 234; Fish Sexual Development Test. (available at: http://www.oecd-ilibrary.org/ docserver/download/9723401e.pdf?expires=1486562793\&id=id\&accn ame=guest\&checksum=7923067145587667BED2748A80CE3DB9)

OECD 2012 Guidance Document on Standardised Test Guidelines for Evaluating Chemicals for Endocrine Disruption. Series on Testing and Assessment. No. 150. (available at: http://www.oecd.org/ officialdocuments/publicdisplaydocumentpdf/?cote=env/jm/ mono(2012)22\&doclanguage $=\mathrm{en}$ )

Ouadah-Boussouf N \& Babin PJ 2016 Pharmacological evaluation of the mechanisms involved in increased adiposity in zebrafish triggered by the environmental contaminant tributyltin. Toxicology and Applied Pharmacology 294 32-42. (doi:10.1016/j.taap.2016.01.014)

Perz-Edwards A, Hardison NL \& Linney E 2001 Retinoic acid-mediated gene expression in transgenic reporter zebrafish. Developmental Biology 229 89-101. (doi:10.1006/dbio.2000.9979)

Pippal JB, Cheung CM, Yao YZ, Brennan FE \& Fuller PJ 2011 Characterization of the zebrafish (Danio rerio) mineralocorticoid receptor. Molecular and Cellular Endocrinology 332 58-66. (doi:10.1016/j.mce.2010.09.014)

Pittlik S, Domingues S, Meyer A \& Begemann G 2008 Expression of zebrafish aldh1a3 (raldh3) and absence of aldh1a1 in teleosts. Gene Expression Patterns 8 141-147. (doi:10.1016/j.gep.2007.11.003)

Riu A, Grimaldi M, le Maire A, Bey G, Phillips K, Boulahtouf A, Perdu E, Zalko D, Bourguet W \& Balaguer P 2011 Peroxisome proliferatoractivated receptor gamma is a target for halogenated analogs of bisphenol A. Environmental Health Perspectives 119 1227-1232. (doi:10.1289/ehp.1003328)

Rizvi YQ, Mehta CS \& Oyekan A 2013 Interactions of PPAR-alpha and adenosine receptors in hypoxia-induced angiogenesis. Vascular Pharmacology 59 144-151. (doi:10.1016/j.vph.2013.09.001)

Samarut E, Gaudin C, Hughes S, Gillet B, de Bernard S, Jouve PE, Buffat L, Allot A, Lecompte O, Berekelya L, et al. 2014 Retinoic acid receptor subtype-specific transcriptotypes in the early zebrafish embryo. Molecular Endocrinology 28 260-272. (doi:10.1210/me.20131358)

Samarut E, Fraher D, Laudet V \& Gibert Y 2015 ZebRA: an overview of retinoic acid signaling during zebrafish development. Biochimica et Biophysica Acta 1849 73-83. (doi:10.1016/j. bbagrm.2014.05.030)

Sassi-Messai S, Gibert Y, Bernard L, Nishio S, Ferri Lagneau KF, Molina J Andersson-Lendahl M, Benoit G, Balaguer P \& Laudet V 2009 The phytoestrogen genistein affects zebrafish development through two different pathways. PLOS ONE 4 e4935. (doi:10.1371/journal. pone.0004935)

Segner H 2009 Zebrafish (Danio rerio) as a model organism for investigating endocrine disruption. Comparative Biochemistry and Physiology Part C: Toxicology and Pharmacology 149 187-195. (doi:10.1016/j.cbpc.2008.10.099)

Shimozono S, Iimura T, Kitaguchi T, Higashijima S \& Miyawaki A 2013 Visualization of an endogenous retinoic acid gradient across embryonic development. Nature 496 363-366. (doi:10.1038/ nature12037)

Spoorendonk KM, Peterson-Maduro J, Renn J, Trowe T, Kranenbarg S, Winkler C \& Schulte-Merker S 2008 Retinoic acid and Cyp26b1 are critical regulators of osteogenesis in the axial skeleton. Development 135 3765-3774. (doi:10.1242/dev.024034) 
Tallafuss A, Hale LA, Yan YL, Dudley L, Eisen JS \& Postlethwait JH 2006 Characterization of retinoid-X receptor genes rxra, rxrba, rxrbb and rxrg during zebrafish development. Gene Expression Patterns 6 556-565. (doi:10.1016/j.modgep.2005.10.005)

Tiefenbach J, Moll PR, Nelson MR, Hu C, Baev L, Kislinger T \& Krause HM 2010 A live zebrafish-based screening system for human nuclear receptor ligand and cofactor discovery. PLOS ONE 5 e9797. (doi:10.1371/journal.pone.0009797)

Tingaud-Sequeira A, Andre M, Forgue J, Barthe C \& Babin PJ 2004 Expression patterns of three estrogen receptor genes during zebrafish (Danio rerio) development: evidence for high expression in neuromasts. Gene Expression Patterns 4 561-568. (doi:10.1016/j. modgep.2004.02.002)

Tingaud-Sequeira A, Ouadah N \& Babin PJ 2011 Zebrafish obesogenic test: a tool for screening molecules that target adiposity. Journal of Lipid Research 52 1765-1772. (doi:10.1194/jlr.D017012)

Tohme M, Prud'homme SM, Boulahtouf A, Samarut E, Brunet F, Bernard L, Bourguet W, Gibert Y, Balaguer P \& Laudet V 2014 Estrogen-related receptor gamma is an in vivo receptor of bisphenol A. FASEB Journal 28 3124-3133. (doi:10.1096/fj.13240465)

Tong SK, Mouriec K, Kuo MW, Pellegrini E, Gueguen MM, Brion F, Kah O \& Chung BC 2009 A cyp19a1b-gfp (aromatase B) transgenic zebrafish line that expresses GFP in radial glial cells. Genesis $\mathbf{4 7}$ 67-73. (doi:10.1002/dvg.20459)

Waxman JS \& Yelon D 2007 Comparison of the expression patterns of newly identified zebrafish retinoic acid and retinoid $\mathrm{X}$ receptors. Developmental Dynamics 236 587-595. (doi:10.1002/dvdy.21049)

White RJ, Nie Q, Lander AD \& Schilling TF 2007 Complex regulation of cyp26a1 creates a robust retinoic acid gradient in the zebrafish embryo. PLoS Biology 5 e304. (doi:10.1371/journal.pbio.0050304)

Wiseman EM, Bar-El Dadon S \& Reifen R 2016 The vicious cycle of vitamin A deficiency: a review. Critical Reviews in Food Science and Nutrition [in press]. (doi:10.1080/10408398.2016.1160362)

Yahyavi M, Abouzeid H, Gawdat G, de Preux AS, Xiao T, Bardakjian T, Schneider A, Choi A, Jorgenson E, Baier H, et al. 2013 ALDH1A3 loss of function causes bilateral anophthalmia/microphthalmia and hypoplasia of the optic nerve and optic chiasm. Human Molecular Genetics 22 3250-3258. (doi:10.1093/hmg/ddt179)

Yong EL, Li J \& Liu MH 2008 Single gene contributions: genetic variants of peroxisome proliferator-activated receptor (isoforms alpha, beta/ delta and gamma) and mechanisms of dyslipidemias. Current Opinion in Lipidology 19 106-112. (doi:10.1097/MOL.0b013e3282f64542)

Zhao Y, Zhang K, Giesy JP \& Hu J 2015 Families of nuclear receptors in vertebrate models: characteristic and comparative toxicological perspective. Scientific Reports 5 8554. (doi:10.1038/srep08554)

Received in final form 14 April 2017

Accepted 20 April 2017

Accepted Preprint published online 24 April 2017 http://jme.endocrinology-journals.org DOI: 10.1530/JME-17-0031
() 2017 Society for Endocrinology Printed in Great Britain
Published by Bioscientifica Ltd 